(n)

\title{
MicroRNAs in the tumour microenvironment: big role for small players
}

\author{
Patsy Soon ${ }^{1,2}$ and Hippokratis Kiaris ${ }^{3}$ \\ ${ }^{1}$ Cancer Genetics, Hormones and Cancer, Kolling Institute of Medical Research, University of Sydney, Level 9, \\ Kolling Building, Royal North Shore Hospital, St Leonards, Sydney, New South Wales, Australia \\ ${ }^{2}$ Department of Surgery, South Western Sydney Clinical School, Bankstown Hospital, University of New South Wales, \\ Sydney, New South Wales, Australia \\ ${ }^{3}$ Department of Biochemistry, University of Athens Medical School, M. Asias 75, 11527 Athens, Greece
}

Correspondence should be addressed to $\mathrm{P}$ Soon or $\mathrm{H}$ Kiaris Emails patsy.soon@sydney.edu.au or hkiaris@med.uoa.gr

\begin{abstract}
MicroRNAs (miRNAs) represent a class of small non-coding RNAs with an important

regulatory role in various physiological processes as well as in several pathologies including cancers. It is noteworthy that recent evidence suggests that the regulatory role of miRNAs during carcinogenesis is not limited to the cancer cells but they are also implicated in the activation of tumour stroma and its transition into a cancer-associated state. Results from experimental studies involving cells cultured in vitro and mice bearing experimental tumours, corroborated by profiling of clinical cancers for miRNA expression, underline this role and identify miRNAs as a potent regulator of the crosstalk between cancer and stroma cells. Considering the fundamental role of the tumour microenvironment in determining both the clinical characteristics of the disease and the efficacy of anticancer therapy, miRNAs emerge as an attractive target bearing important prognostic and therapeutic significance during carcinogenesis. In this article, we will review the available results that underline the role of miRNAs in tumour stroma biology and emphasise their potential value as tools for the management of the disease.
\end{abstract}

Key Words

- molecular biology

- carcinoma

\section{Importance of the tumour microenvironment}

The tumour microenvironment plays an increasingly appreciated role in tumorigenesis. During neoplastic development, a series of changes occur in the tumour stroma that ultimately promote tumour growth and affect not only the clinicopathological profile of the tumour but also the efficacy of anticancer therapy. Cancer has been postulated to be a physiological response to an abnormal stromal environment (Barcellos-Hoff \& Medina 2005). Indeed, certain similarities between carcinogenesis and wound healing have been recognised leading to the suggestion that cancers can be viewed as 'wounds that do not heal' (Haddow 1972, Dvorak 1986). Interaction between the tumour and stromal cells can determine the fate of the tumour cells - whether they remain in a dormant state or progress into invasive and eventually metastatic cancer. Therefore, the establishment of a complex reciprocal network of communication between the cancer cells and cells of the microenvironment, such as fibroblasts, is imperative in order to fuel tumour growth (Kiaris et al. 2008).

Various soluble factors that are abundant in the tumour microenvironment have been implicated in the activation of the tumour stroma. The significance of microenvironment has been demonstrated by early

Published by Bioscientifica Ltd. 
experiments demonstrating that loss of TGF $\beta$ signalling in fibroblasts leads to development of increased amounts of stromal cells and prostate intraepithelial neoplasia, indicating that loss of TGF $\beta$ signalling can facilitate neoplastic progression (Bhowmick et al. 2004). Stromal interactions with the epithelial cells can be altered by external influences such as radiation therapy. Barcellos-Hoff \& Ravani (2000) demonstrated that COMMA-D mammary epithelial cells, which harbour P53 (TP53) mutations in both alleles but which are non-tumorigenic, developed larger tumours more rapidly after implantation into mammary fat pads that had been irradiated compared with sites that had not been irradiated. These data indicate that radiation-induced changes in the stromal microenvironment can influence epithelial cells and contribute to tumour progression in vivo, a finding that in turn implies that activation of a paracrine response programme, likely related to DNA damage in stromal cells, is pro-oncogenic. Indeed, recent findings have shown that during chemotherapy treatment, stromal fibroblasts are engaged in a mitogenic programme for which $C D K 8$ plays a major role and ultimately reduces therapeutic drug efficacy (Porter et al. 2012).

Besides changes in the expression profile of the stromal cells, it has been suggested that the genetic changes present in the tumour and stromal compartments are a result of tumour and stromal co-evolution (Wallace et al. 2011). To that end, it has been shown that the stromal fibroblasts of human breast and other cancers frequently bear mutations in specific tumour suppressor genes, such as PTEN and TP53. It is noteworthy that these mutations have occurred in the microenvironment independently of the cancer cells implying different genetic origin from the lesions that may occur in the cancer cells (Kurose et al. 2002, Patocs et al. 2007, Farmaki et al. 2012). These genetic alterations of the stromal cells have been shown to affect tumorigenesis (Kiaris et al. 2005, Trimboli et al. 2009, Addadi et al. 2010, Guo et al. 2013) and anticancer drug efficacy considerably (Lafkas et al. 2008).

The clinical relevance of the findings derived from experimental tumour studies has been shown by analyses of human cancers in which the expression profile of the stromal tissue was sufficient to predict prognosis of the disease and chemotherapeutic drug efficacy. Using laser capture microdissection to isolate breast cancer stroma compared with normal breast stroma at least $2 \mathrm{~mm}$ away from the cancer, one study identified a 26-gene stromal gene expression signature as a prognostic indicator independent of other factors such as patient age, tumour grade, oestrogen receptor or human epithelial growth factor receptor type 2 and lymph node status (Finak et al. 2008). Another study found that a stroma-related gene signature was able to predict resistance to neoadjuvant chemotherapy in breast cancer patients (Farmer et al. 2009). These studies indicate the importance of the tumour stroma as it contributes to outcome of the patient as well.

\section{Components of the tumour microenvironment}

The tumour microenvironment consists of a multitude of cell types including fibroblasts, endothelial cells and inflammatory cells. Fibroblasts are the most abundant cells in the tumour microenvironment (Micke \& Ostman 2005). While normal fibroblasts have been shown to prevent tumour growth and invasiveness in the early stages of carcinogenesis (Paland et al. 2009), cancerassociated fibroblasts (CAFs) create an environment that is conducive to tumour initiation and progression (Olumi et al. 1999, Hayward et al. 2001, Orimo et al. 2005, Soon et al. 2013). The progressive transition of stromal fibroblasts and their commitment into a cancer-associated state is characterised by specific changes in their secretory profile that includes, among others, the production of an array of chemokines that in turn attract inflammatory cells into the region (Orimo et al. 2005) generating a proinflammatory microenvironment. The fibroblasts and the inflammatory cells then release growth factors and act either directly on the cancer cells stimulating their proliferation and/or inhibiting apoptosis or indirectly by promoting tumour growth and stimulating angiogenesis (Coussens \& Werb 2002). Indeed, the intrinsic relationship between chronic inflammation and cancer has been hypothesised as early as 150 years ago by Virchow (Balkwill \& Mantovani 2001). Endothelial cells together with pericytes and smooth muscle cells make up blood vessels that are of prime importance in the tumour microenvironment if the tumour is to grow beyond 2-3 mm or metastasise (Folkman 1971).

While the origin of CAFs is not fully defined, they are thought to arise from several sources. Depending on the exact type of cancer, up to $40 \%$ of CAFs can be derived from bone marrow precursor cells (Ishii et al. 2003, Direkze et al. 2004) that are attracted to the site of the neoplastic growth from the circulation and populate the growing tumour. CAFs may also originate from epithelial cancer cells that have undergone epithelial-to-mesenchymal transition (Petersen et al. 2003). If this is the case, as the stromal fibroblasts originate from the neoplastic cells, they are expected to bear genetic lesions in common, a fact that

Published by Bioscientifica Ltd. 
can profoundly affect their behaviour. In addition, CAFs may arise from resident fibroblasts that have been subjected to a myofibroblast differentiation programme that is marked by the neo-expression of smooth muscle actin (SMA) and represents a hallmark for their commitment into a cancer-associated state (Ronnov-Jessen \& Petersen 1993). Recent evidence indicates that specific microRNAs (miRNAs) have emerged as major regulators of this paracrine activity and of the transition of the fibroblasts into the cancer-associated state. As discussed later, miR-21 (Yao et al. 2011), miR-31, -214 and -155 (Mitra et al. 2012) appear to play a role in differentiation of normal fibroblasts to CAFs.

\section{miRNAs and their role in tumorigenesis}

The term miRNA was coined in 2001 to describe a new class of small non-coding regulators (Ruvkun 2001). miRNAs are small, non-coding RNAs that negatively regulate gene expression in a sequence-specific manner. They interact with target mRNAs to induce cleavage and degradation. Alternatively, they may trigger mRNA deadenylation or directly inhibit protein translation. Thus, miRNAs may suppress the expression of their target genes by a variety of mechanisms, by reducing protein expression without altering the mRNA levels (Esquela-Kerscher \& Slack 2006) or by reducing mRNA levels. Lee et al. (1993), while studying heterochronic genes in Caenorhabditis elegans, found that lin4, the first miRNA to be identified, was located in an intron of another gene and functioned to negatively regulate lin14. A new class of small RNAs was thus discovered. Initially, it was thought that this paradoxical mode of gene regulation was a unique feature of $C$. elegans. However, the subsequent discovery of a second miRNA, let7, which negatively regulates lin41 and hbl1, suggested that it reflects a more generalised phenomenon (Pasquinelli et al. 2000). Let7 was found to be phylogenetically conserved (Reinhart et al. 2000), which led to the speculation that this new class of RNAs play a major role in gene regulatory networks. Subsequently, many other miRNAs were identified in both plants and animals. Despite the specific discrepancies in their mode of action, miRNAs always operate as regulators of gene expression (Lau et al. 2001, Lee \& Ambros 2001).

Currently, miRBase version 20 includes 30424 mature miRNAs in 206 species with a total of 2578 mature miRNAs described in humans (Kozomara \& Griffiths-Jones 2011). In animals, miRNAs are transcribed from intergenic or intronic DNA as large precursors termed pri-miRNAs.
A single pri-miRNA may encode for up to six miRNA precursors. Subsequently, these hairpin loop structures undergo successive enzymatic processing by Drosha, Pasha and Dicer into their mature, usually 22-nucleotide long, double-stranded RNA termed the miRNA:miRNA* duplex. The asterisk $\left({ }^{*}\right)$, or $3 p$ strand, denotes the presence of the 'passenger' strand that is represented at lower levels in the steady state and is usually degraded. The whole process takes place initially in the nucleus and subsequently in the cytoplasm where cleavage by Dicer occurs. This duplex is incorporated into the RNA-induced silencing complex and the mature miRNA strand is preferentially retained (Du \& Zamore 2005).

More than $50 \%$ of the genomes are likely targets of specific miRNA regulation (Friedman et al. 2009). miRNAs have been implicated in a variety of cellular processes such as development, differentiation, growth and apoptosis (Esquela-Kerscher \& Slack 2006). There is an increasing recognition that miRNAs are involved in carcinogenesis. Such miRNAs, termed oncomirs, act as tumour suppressor or oncogenes (He et al. 2005, Esquela-Kerscher \& Slack 2006) depending on whether their specific targets are oncogenic or anti-oncogenic transcripts respectively. A number of malignancies have been associated with characteristic miRNA signatures (Lu et al. 2005, Calin \& Croce 2006). miRNAs have been found to be dysregulated in cancers compared with normal tissue. For example, miR143 and -145 have been found to be down-regulated in colorectal (Michael et al. 2003) and breast cancers (Iorio et al. 2005), while miR-21 has been found to be up-regulated in glioblastomas (Chan et al. 2005, Ciafre et al. 2005) and breast cancers (Iorio et al. 2005). Furthermore, various miRNAs represent targets of specific oncogenes, such as a cluster of Myc-induced miRNAs located on chromosome 13 (miR-17-5p and -20a), which suppresses E2F1 expression (O'Donnell et al. 2005). In addition, miR-145 has been identified as a TP53 target gene. Considering that there is deregulated expression and genomic alterations of TP53 in stromal cells, this finding may have important implications on how aberrant expression of this and other miRNAs may play a role in the regulation of the tumour microenvironment (Sachdeva et al. 2009).

miRNA-related modulation of gene expression is not limited to the regulation of cell autonomous phenomena that exclusively affect the phenotype of the cells subjected to the differential production of the specific miRNA. Stromal cells also express important regulatory miRNAs that can influence the phenotype of adjacent epithelial cells. Characteristic are the results of a study by Ucar et al. (2010) miR-212/-132 null female mice were generated, and

Published by Bioscientifica Ltd. 
by transplanting WT mammary epithelial cells into fat pads of mutant mice and vice versa, they found that miR-212/-132 expression in stromal cells, and not epithelial cells, is essential for normal ductal development of the mammary gland. This study demonstrates that expression of miRNAs by stromal cells influences development of breast tissue. In view of this and various other analogous findings, and considering the important role of tumour stroma in carcinogenesis, it is not surprising that miRNAs produced by cells of the microenvironment, and particularly from stromal fibroblasts, will profoundly affect tumour growth. Indeed, various such stromaderived miRNAs have been identified and their role in tumorigenesis has begun to be unravelled.

This review focuses on the miRNAs involved in the induction of specific changes in the tumour microenvironment, particularly in the CAFs, and their role in inducing tumour progression. A number of studies have revealed the significant role of miRNAs in CAFs and other components of the tumour microenvironment. These studies are detailed below.

\section{Differentiation of fibroblasts to CAFs}

Recent evidence indicates that specific miRNAs have emerged as regulators of the transition of the fibroblasts into the cancer-associated state. Yao et al. studied primary ovarian CAFs as well as human fetal lung fibroblast cell line MRC-5. Using TGF $\beta$ or conditioned medium from epithelial cancer cells, which included OVCAR3 (ovarian cancer cell line) and HCT116 (colon cancer cell line), they were able to induce expression of $\alpha$-SMA, a hallmark of CAFs, in MRC-5 cells. They found that both TGF $\beta$ and conditioned medium from cancer cells were able to increase expression of miR-21 up to 5.8-fold. They confirmed that over-expression and under-expression of miR-21 in MRC-5 cells resulted in increased and decreased expression of $\alpha$-SMA in these cells respectively. In addition, they showed by luciferase assay that programmed cell death 4 (PDCD4) is a target of miR-21 that induces CAF characteristics in MRC-5 cells (Yao et al. 2011).

In another study involving ovarian cancers, Mitra et al. discovered that miR-31 and -214 were downregulated whereas miR-155 was up-regulated in the CAFs compared with normal fibroblasts. Subsequent modulation of the expression of these miRNAs showed that their deregulated expression was sufficient to convert normal fibroblasts to CAFs and vice versa and has identified CCL5 chemokine as a target of miR-214 (Mitra et al. 2012).

\section{Cancer-associated fibroblasts}

Genetic ablation of PTEN in stromal fibroblasts promotes tumorigenesis in the mammary epithelium (Bronisz et al. 2012). Analysis of the secretome profile of PTEN-null fibroblasts by Bronisz et al. identified miR-320 as a major regulator of this paracrine response. miR-320 expression was significantly reduced in PTEN-null mouse mammary fibroblasts (MMFs). PTEN-null MMFs when injected into immunocompromised mice with a mouse mammary epithelial tumour cell line developed fourfold greater tumour growth when compared with $P T E N^{+/+}$MMFs. This was reversed with restoration of miR-320 expression in PTEN-null MMFs. Restoration of miR-320 expression also resulted in less invasive tumours that were less vascular. The authors also examined expression of miR-320 in stromal and epithelial cells of 126 invasive breast cancers and matched normal samples. They found miR-320 expression in both epithelial and stromal compartments, with lower expression in invasive cancer compared with normal breast tissue, consistent with their in vivo findings of lower miR-320 expression being associated with a more malignant phenotype. Mass spectrometry analysis of conditioned media from PTEN-null MMFs over-expressing miR-320 compared with control PTEN-null MMFs revealed 54 proteins that were differentially expressed between the two groups. These were categorised into three groups - proteins that were increased in PTEN-null MMFs that returned to near-normal levels with re-introduction of miR-320 - the proteins included matrix metallopeptidase 9 (MMP9), MMP2, bone morphogenetic protein 1 (BMP1), lysyl oxidase-like 2 (LOXL2) and elastin microfibril interface 2 (EMILIN2); proteins that were down-regulated in PTEN-null MMPs and that were up-regulated with re-introduction of miR-320 included thrombospondin 1 (THBS1) and secreted frizzledrelated protein 1 (SFRP1); and proteins that were unaffected by miR-320 expression which included cathepsin B (CTSB). The human homologues of the 54 murine differentially expressed proteins were able to distinguish tumour from normal stoma and actually correlated with clinical outcome based on stromal gene expression in breast cancer patients. Ets 2 was also identified as a direct target of miR-320. Re-introduction of miR-320 into PTEN-null MMFs resulted in a decrease in ETS2 protein levels. In stromal fibroblasts, a PTEN-miR-320-Ets2 tumour suppressor axis therefore exists, which is involved in intercellular communication within the tumour microenvironment and play a role in pathological and molecular events in human breast cancers (Bronisz et al. 2012).

Published by Bioscientifica Ltd. 
miR-148a has been found to be significantly downregulated in CAFs of endometrial cancer compared with matched normal fibroblasts. Up-regulation of miR-148a expression by lentiviral transfection in CAFs did not alter the growth or morphology of the cells but resulted in a decreased ability of the CAFs to induce migration in endometrial cancer cell lines. Conditioned medium of CAFs expressing miR-148a also decreased the invasive phenotype of endometrial cancer cell lines cultured in three-dimensional culture. WNT1OB was identified as a direct target of miR-148a, which stimulated migration of endometrial cancer cells (Aprelikova et al. 2013). This link between miR-148a and Wnt signalling is also suggested by the identification of this miRNA as a regulator of adipogenesis by suppressing the Wnt pathway (Qin et al. 2010).

Aprelikova et al. (2010) performed miRNA profiling of five matched pairs of endometrial CAFs and normal fibroblasts and found 11 miRNAs to be significantly differentially expressed between the two groups. Among these, miR-31 was down-regulated, and miR-503, -424 and -542-3p, all located on chromosome Xq26.3, were up-regulated in CAFs compared with normal fibroblasts. Fibroblasts over-expressing miR-31, when co-cultured with endometrial cancer cells, caused decreased migration and invasion but no change in proliferation in the endometrial cancer cells. SATB2, a predicted target of miR-31, was found to be over-expressed in CAFs compared with normal fibroblasts. Over-expression of miR-31 in CAFs decreased SATB2 mRNA and protein levels and luciferase assays confirmed that $S A T B 2$ is a direct target of miR-31. SATB2 was transduced into normal fibroblasts (which have lower expression of SATB2) and co-culture of these fibroblasts with endometrial cancer cells resulted in increased migration and invasion of the cancer cells. Expression of miR-31 in CAFs therefore suppresses cancer cell motility and invasion in part by targeting SATB2 (Aprelikova et al. 2010). Mitra et al. (2012) also found that down-regulation of miR-31 and -213 and downregulation of miR-155 resulted in enhanced CAF migration as well as invasion of ovarian cancer cells co-cultured with these CAFs, an effect mediated by CCL5, a target of these miRNAs.

Similarly, Zhao et al. performed miRNA profiling of six pairs of matched CAFs and normal fibroblasts from breast cancer patients. They identified three up-regulated (miR-221-5p, -31-3p and -221-3p) and eight downregulated (miR-205, -200b, -200c, -141, -101, -342-3p, let-7g and -26b) miRNAs in CAFs compared with matched normal fibroblasts (Zhao et al. 2012). Interestingly, there was no overlap with the results found in different CAFs compared with their matched normal fibroblasts, which could in part be explained by tissue specificity of miRNAs (Liu et al. 2004).

In situ hybridization analysis of CAFs from prostate cancer suggested that miR-15 and -16 are down-regulated in CAFs compared with normal fibroblasts. CAFs transduced with miR-15 and -16 had decreased rate of proliferation and underwent apoptosis over the course of 1-3 weeks. Fibroblasts transduced with miR-15 and -16, when co-cultured with prostate cancer cells, impaired migration of the cancer cells as well as decreased proliferation by decreasing the proportion of cells in the S-phase and increasing the number of cells in G0-G1 phase. Reconstitution of miR-15 and -16 in CAFs therefore alters the crosstalk between the microenvironment and the cancer resulting in reduced cancer expansion capabilities. CAFs over-expressing miR-15 and -16 were found to express lower levels of FGF2 and FGFR1 that act on both the stromal and the cancer cells. Using luciferase assays, these two genes were found to be direct targets of miR-15 and -16 . Mice were then inoculated with a mixture of prostate epithelial cells and either empty vector-treated CAFs or miR-15/-16-transduced CAFs. Empty vectortreated CAFs strongly promoted tumour growth compared with miR-15/-16-transduced CAFs. On haematoxylin and eosin staining, tumours generated from cancer cells mixed with empty vector-treated CAFs appeared to recruit stromal cells and developed an extensive invasive front. There was also much less expression of FGF2 and a reduction in blood vessels in both epithelial and stromal compartments of cancers generated from cancer cells combined with miR-15/-16-transduced CAFs. The data indicate that miR-15/-16 transduction of CAFs affects tumour microenvironment crosstalk (Musumeci et al. 2011). Furthermore, miR-16 promoted the differentiation of bone marrow mesenchymal stem cells towards myogenic phenotype, suggesting that interference of this miRNA with the function of stroma is not characteristic only of pathological conditions (Liu et al. 2012).

\section{Hypoxia}

Hypoxia is a key feature of the tumour microenvironment. Tumours develop hypoxia as a result of impaired angiogenesis (Harris 2002). Tumours that exhibit low oxygen tension are associated with poor prognosis and resistance to therapy (Hockel et al. 1996, Kulshreshtha et al. 2007a). Hypoxia-inducible factors (HIFs) are transcription factors responsible for the expression of a

Published by Bioscientifica Ltd 
number of genes responsible for adaptation of cells to low oxygen environment (Harris 2002). By exposing breast and colon cancer cells to hypoxic conditions, Kulshreshtha et al. identified a number of miRNAs that were induced by hypoxia. These include miR-21, -23a, -23b, -24, -26a, -26b, -27a, -30b, -93, -103, -103, -106a, $-107,-125 b,-181 a,-181 b,-181 c,-192,-195,-210$ and -213 as well as miRNAs that are down-regulated by hypoxia including miR-122a, -565, -195, -30e-5p, -374, -19a, -101, $-424,-29 b,-186,-141,-320,-422 b,-197,-15 b,-16,-20 a$, $-20 \mathrm{~b},-30 \mathrm{~b}$ and -224 . Many of these hypoxia-regulated miRNAs have also been found to be altered in cancers, suggesting that they play a role in tumorigenesis as well (Kulshreshtha et al. 2007b). Of the studies, which have looked at hypoxia-regulated miRNAs, miR-210 has been the single miRNA consistently found to be induced by hypoxia (Kulshreshtha et al. 2007b, Camps et al. 2008, Fasanaro et al. 2008).

Over-expression of miR-210, reflecting hypoxia, in cancers is associated with worse prognosis (Camps et al. 2008). Exposing endothelial cells in the microenvironment to hypoxic conditions also results in increased expression of miR-210 via HIF1 $\alpha$. miR-210 in turn downregulated Ephrin A3 resulting in decreased capillary-like formation and migration of the endothelial cells (Fasanaro et al. 2008).

\section{Extracellular matrix and angiogenesis}

The extracellular matrix (ECM), consisting of a complex network of macromolecules, is an important part of the tumour microenvironment ( $\mathrm{Lu}$ et al. 2012). miRNA expression by the cancer cells can alter the tumour microenvironment by inhibiting genes involved in angiogenesis and ECM signalling resulting in inhibition of metastasis. miR-29b has been reported to be downregulated in hepatocellular carcinomas (HCCs) and associated with worse patient prognosis (Xiong et al. 2010). Fang et al. found that endothelial cells grown in medium conditioned by HCC cells transfected with miR29b developed fewer capillary-like structures compared with those transfected with negative control. In vivo experiments performed on mice with HCC cell lines transfected with miR-29b or negative control confirmed smaller tumours with lower blood vessel density and fewer and smaller intrahepatic metastases in miR-29btransfected HCC cells. miR-29b was found to exert its function by suppressing pro-metastatic genes that include MMP2 (Fang et al. 2011), ANGPTL4, LOX, MMP9 and VEGFA (Chou et al. 2013). miR-29b itself is regulated by
GATA3 (Chou et al. 2013), a key regulator of mammary gland formation (Asselin-Labat et al. 2007). miR-29b and GATA3 therefore play an important role in inhibition of metastasis.

miRNAs have also been found to affect endothelial cells, thus likely playing a role in angiogenesis during tumour development. Png et al. found that miR-126 suppresses metastatic recruitment of endothelial cells, angiogenesis and colonization via IGFBP2, PITPNC1 and MERTK. miR-126 regulates endothelial recruitment to metastatic breast cancer cells regardless of anatomical location. Over-expression of miR-126 strongly inhibited endothelial recruitment while knockdown of miR-126 significantly increased endothelial cell recruitment. miR-126 was noted to suppress eight genes ( $A B C B 9$, IGFBP2, MERTK, PITPNC1, PSAT1, ITGB4, SHMT2 and VIPR1), and breast cancers that over-expressed these genes were more likely to develop distal metastasis and have shorter metastasis-free survival. In addition, stage 3 and 4 primary breast cancers were found to significantly over-express a subset of these genes (IGFBP2, MERTK and PITPNC1) compared with stage 1 and 2 cancers. Knockdown of IGFBP2, MERTK and PITPNC1 decreased the ability of cells to metastasize as well as reduced metastatic endothelial density and functional vessel content. Overexpression of these three genes in miR-126 over-expressing cells rescued the ability of cancer cells to recruit endothelial cells, indicating that IGFBP2, MERTK and PITPNC1 are direct targets of miR-126 and required for metastatic colonisation and endothelial recruitment (Png et al. 2012). Consistent with the role of miR-126 in endothelial cells, miR-126 has been found to be down-regulated in colon (Guo et al. 2008) and gastric (Feng et al. 2010) cancers.

Besides its role in regulating the recruitment of the endothelial cells, miR-126 is also capable of suppressing the recruitment of monocytes and thus inhibiting the development of lung metastases of breast cancers (Zhang et al. 2013). Interestingly, this activity is produced by both miR-126 and independently by its passenger miR-126(*). In this model, the anti-metastatic effect is mediated directly by suppressing the expression of SDF1a and indirectly by suppressing CCL2 chemokine by a manner that depends on SDF1a.

\section{Immune cells}

A number of papers have demonstrated that CAFs play a role in attracting the immune cells to the site of the cancer (Augsten et al. 2009, Erez et al. 2010, Hembruff et al. 2010). Hembruff et al. (2010) found that over-expression of the

Published by Bioscientifica Ltd 
chemokine CCL2 by fibroblasts and co-culture with 4T1 mammary carcinoma cells in vivo resulted in enhanced recruitment of tumour-associated macrophages as well as increased proliferation of the primary tumour and liver metastases. In addition to recruiting immune cells to the site of the cancer, CAFs can also alter the functional activation of these cells resulting in an immunosuppressive tumour-promoting microenvironment (Liao et al. 2009, Kim et al. 2012). Various chemokines have been identified as the factor(s) secreted by CAFs, which influence immune cells (Raz \& Erez 2013). Finally, secretion of miRNAs by CAFs or immune cells may also play a role in the interaction between different cell types of the tumour microenvironment (Chen et al. 2012).

\section{Future perspectives}

The elucidation of the role of miRNAs in tumour biology is a rapidly growing field in cancer research because it holds promise for application as markers for the prognosis of the disease as well as targets for the development of novel cancer therapeutics. The advantages of utilising miRNAs as prognostic markers or therapeutic targets have been described in detail elsewhere (Nelson \& Weiss 2008, Garzon et al. 2010). This notion is particularly true for their role in tumour stroma biology because of the prognostic significance as well as their ability to regulate the crosstalk between CAFs and cancer cells (Table 1 and Fig. 1). While a number of miRNAs and some of their gene targets have been identified to play a role in tumour progression via CAFs, much still remains to be elucidated. In particular, while in many cases the intracellular molecular networks that are affected by the deregulation of miRNAs in CAFs have been established, with a few exceptions, the paracrine mediators of the miRNA-mediated response remain obscure. It is conceivable that understanding the identity of these mediators will provide specific markers for understanding the role of miRNAs as regulators of the paracrine activity and will also suggest novel targets for interfering with the activation of the tumour microenvironment. Currently, how miRNAs are deregulated during the activation of the

Table 1 Overview of specific microRNAs and their reported role in the tumour microenvironment.

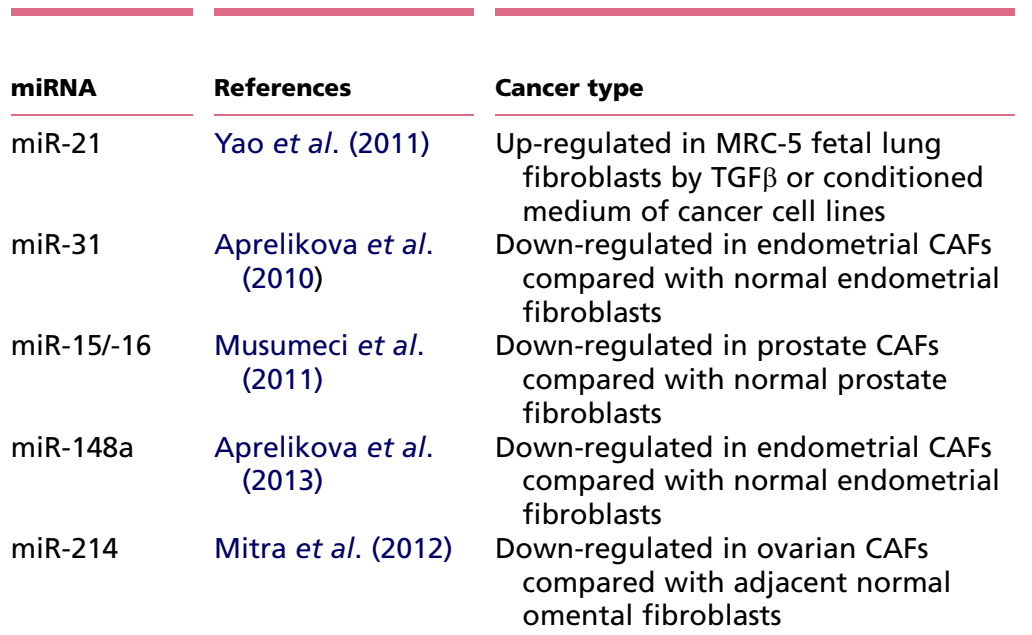

$\operatorname{miR}-320$

Bronisz et al. (2012) Down-regulated in Pten-null mammary ETS2 mouse fibroblasts compared with WT PTEN mammary mouse fibroblasts; also found to be decreased in expression in stromal and epithelial compartments of invasive breast cancer samples compared with normal breast

miR-126 Png et al. (2012)

\begin{tabular}{l}
$\begin{array}{l}\text { Gene } \\
\text { target }\end{array}$ \\
\hline PDCD4 \\
SATB2 \\
FGF2 \\
FGFR1 \\
WNT1OB \\
CCL5 \\
\hline ETS2 \\
\hline IGFBP2 \\
MITPNC \\
\hline
\end{tabular}
cancer

Effect when miRNA level altered

Up-regulation of miR-21 in MRC-5 cells resulted in transdifferentiation to a CAF phenotype

Up-regulation of miR-31 decreases migration and invasion of endometrial cancer cells

Up-regulation of miR-15/-16 impairs migration, decreases proliferation
Up-regulation of miR-148a decreases migration

Decreases CAF migration and invasion of co-cultured ovarian cancer cells. Down-regulation of miR-214 in normal omental fibroblasts resulted in differentiation of these fibroblasts into CAFs

When Pten-null mammary mouse fibroblast co-injected with epithelial cancer cell line in vivo, there was less tumour growth with less invasive and less vascular tumour
Up-regulation of miR-126 suppresses metastatic endothelial recruitment, angiogenesis and colonization

http://erc.endocrinology-journals.org DOI: $10.1530 /$ ERC-13-0119 (c) 2013 Society for Endocrinology Printed in Great Britain 


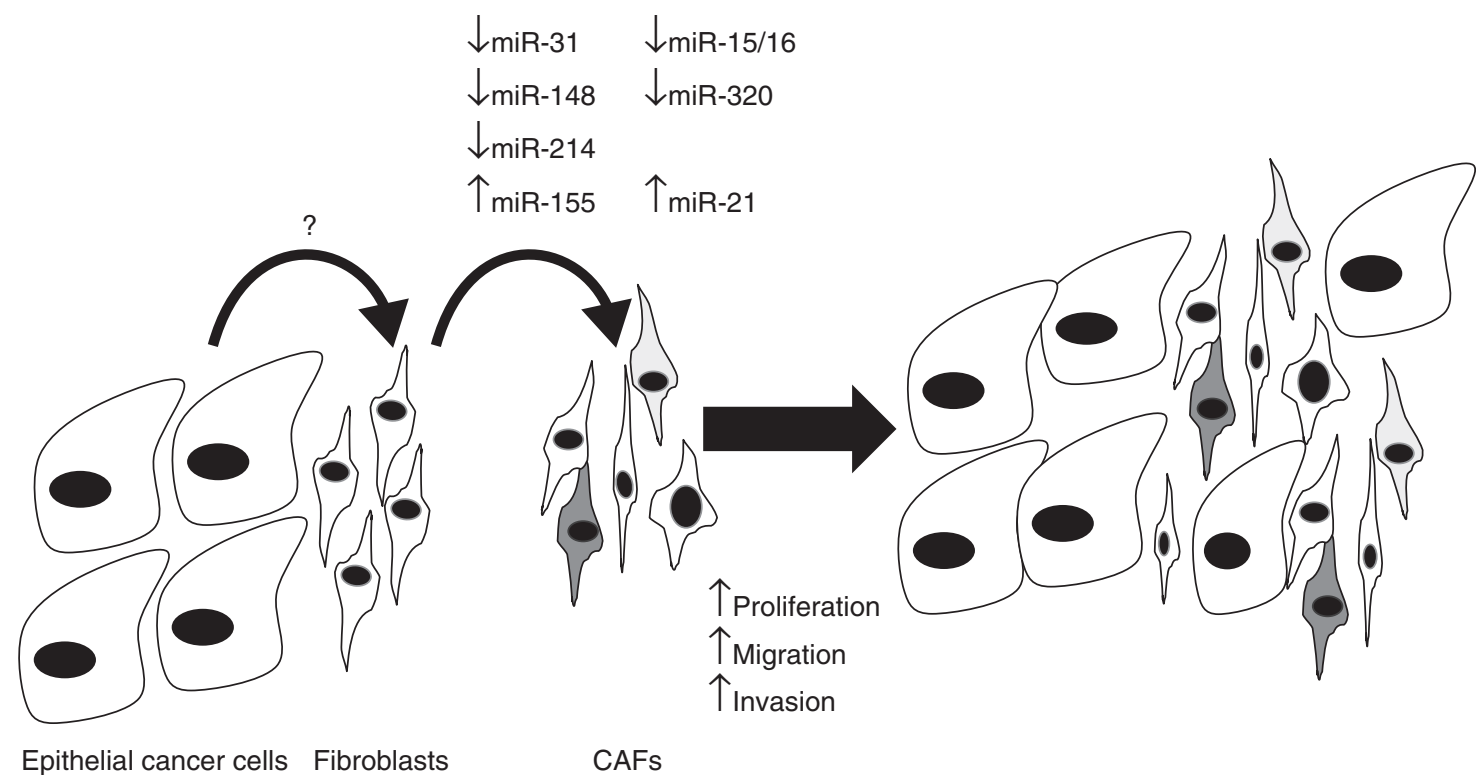

Figure 1

Diagrammatic overview for the possible involvement of microRNAs in the tumour microenvironment. Certain stimuli elicited by the cancer cells cause the modulation of the expression of specific microRNAs in the stromal fibroblasts. These changes in expression of microRNAs are associated with the activation of stromal fibroblasts and the transition into the

stroma in carcinogenesis and, in particular, how specific signals from the cancer cells are integrated into the stromal fibroblasts and induce their transition into CAFs remain poorly understood. Interestingly, the majority of the miRNAs known to date that are differentially expressed in CAFs are down-regulated when compared with normal fibroblasts, implying that they are acting as suppressors of stroma activation. Thus, the identification of an array of miRNAs that may act as activators is anticipated and remains to be confirmed.

Further work is urgently required to deepen our understanding of miRNAs not only within the tumour environment but also within the epithelial cancer cells themselves before miRNAs can be thought of as potential therapeutic targets.

\section{Conclusion}

Although several lines of evidence are available regarding the actual secreted mediators of the paracrine communication between cancer and stromal cells, the intracellular regulators of this process remain poorly understood. The rapid induction of this non-cell autonomous activity following neoplastic development in combination with its pleiotropic activity that apparently affects a cancer-associated fibroblast state, which in turn stimulates the invasion, migration and proliferation of the cancer cells. Cancer cell-independent differential expression of microRNAs in the fibroblasts may also be sufficient for the neoplastic conversion of otherwise normal epithelium.

variety of cellular processes, such as stimulation of cell proliferation, acquisition of resistance to apoptosis, induction of angiogenesis as well as the generation of a pro-inflammatory microenvironment by mobilising cells of the immune system, imposes interesting challenges: It must be a rapid response that should be triggered rapidly following the onset of malignancy, it must be capable of affecting the production of various cytokines and chemokines and at the same time, it should also be very specific as the profile of fibroblasts' activation appears quite homogeneous regardless of the source of the cancer with its variable origin and characteristics. To that end, understanding the regulation of the tumour microenvironment is essential in order to understand basic aspects of tumour biology and may also provide novel targets for therapeutic intervention and tools of prognostic value.

Fibroblasts have been shown conclusively to play a role in tumorigenesis with miRNAs implicated in regulating their transition into the CAF state. Because the tumour stroma, of which CAFs comprise the major component, is able to influence patient outcome, research in the regulatory role of miRNAs in CAFs' biology is needed to unravel the complex interactions between stroma and tumour cells and ultimately to improve overall patient outcome.

Published by Bioscientifica Ltd. 


\section{Declaration of interest}

The authors declare that there is no conflict of interest that could be perceived as prejudicing the impartiality of the review reported.

\section{Funding}

P Soon is funded by the New South Wales Cancer Institute (Clinical Research Fellowship \#09/CRF/2-05) and work in H Kiaris's laboratory is supported by an EXCELLENCE-2011 (ARISTEIA) grant (11EXC311) funded by the European Social Fund-European Union and National Resources.

\section{References}

Addadi Y, Moskovits N, Granot D, Lozano G, Carmi Y, Apte RN, Neeman M \& Oren M 2010 p53 status in stromal fibroblasts modulates tumor growth in an SDF1-dependent manner. Cancer Research 70 9650-9658. (doi:10.1158/0008-5472.CAN-10-1146)

Aprelikova O, Yu X, Palla J, Wei BR, John S, Yi M, Stephens R, Simpson RM, Risinger JI, Jazaeri A et al. 2010 The role of miR-31 and its target gene SATB2 in cancer-associated fibroblasts. Cell Cycle 9 4387-4398. (doi:10.4161/cc.9.21.13674)

Aprelikova O, Palla J, Hibler B, Yu X, Greer YE, Yi M, Stephens R, Maxwell GL, Jazaeri A, Risinger JI et al. 2013 Silencing of miR-148a in cancer-associated fibroblasts results in WNT10B-mediated stimulation of tumor cell motility. Oncogene 32 3246-3253. (doi:10.1038/ onc.2012.351)

Asselin-Labat M-L, Sutherland KD, Barker H, Thomas R, Shackleton M, Forrest NC, Hartley L, Robb L, Grosveld FG, van der Wees J et al. 2007 Gata-3 is an essential regulator of mammary-gland morphogenesis and luminal-cell differentiation. Nature Cell Biology 9 201-209. (doi:10.1038/ncb1530)

Augsten M, Hagglof C, Olsson E, Stolz C, Tsagozis P, Levchenko T, Frederick MJ, Borg A, Micke P, Egevad L et al. 2009 CXCL14 is an autocrine growth factor for fibroblasts and acts as a multi-modal stimulator of prostate tumor growth. PNAS 106 3414-3419. (doi:10.1073/pnas.0813144106)

Balkwill F \& Mantovani A 2001 Inflammation and cancer: back to Virchow? Lancet 357 539-545. (doi:10.1016/S0140-6736(00)04046-0)

Barcellos-Hoff MH \& Ravani SA 2000 Irradiated mammary gland stroma promotes the expression of tumorigenic potential by unirradiated epithelial cells. Cancer Research 60 1254-1260.

Barcellos-Hoff MH \& Medina D 2005 New highlights on stroma-epithelial interactions in breast cancer. Breast Cancer Research 7 33-36. (doi:10.1186/bcr972)

Bhowmick NA, Chytil A, Plieth D, Gorska AE, Dumont N, Shappell S Washington MK, Neilson EG \& Moses HL 2004 TGF- $\beta$ signaling in fibroblasts modulates the oncogenic potential of adjacent epithelia. Science 303 848-851. (doi:10.1126/science.1090922)

Bronisz A, Godlewski J, Wallace JA, Merchant AS, Nowicki MO, Mathsyaraja H, Srinivasan R, Trimboli AJ, Martin CK, Li F et al. 2012 Reprogramming of the tumour microenvironment by stromal PTENregulated miR-320. Nature Cell Biology 14 159-167. (doi:10.1038/ ncb2396)

Calin GA \& Croce CM 2006 MicroRNA signatures in human cancers. Nature Reviews. Cancer 6 857-866. (doi:10.1038/nrc1997)

Camps C, Buffa FM, Colella S, Moore J, Sotiriou C, Sheldon H, Harris AL, Gleadle JM \& Ragoussis J 2008 hsa-miR-210 is induced by hypoxia and is an independent prognostic factor in breast cancer. Clinical Cancer Research 14 1340-1348. (doi:10.1158/1078-0432.CCR-07-1755)

Chan JA, Krichevsky AM \& Kosik KS 2005 MicroRNA-21 is an antiapoptotic factor in human glioblastoma cells. Cancer Research 65 6029-6033. (doi:10.1158/0008-5472.CAN-05-0137)
Chen X, Liang H, Zhang J, Zen K \& Zhang CY 2012 Secreted microRNAs: a new form of intercellular communication. Trends in Cell Biology 22 125-132. (doi:10.1016/j.tcb.2011.12.001)

Chou J, Lin JH, Brenot A, Kim J-W, Provot S \& Werb Z 2013 GATA3 suppresses metastasis and modulates the tumour microenvironment by regulating microRNA-29b expression. Nature Cell Biology 15 201-213. (doi:10.1038/ncb2672)

Ciafre SA, Galardi S, Mangiola A, Ferracin M, Liu CG, Sabatino G, Negrini M, Maira G, Croce CM \& Farace MG 2005 Extensive modulation of a set of microRNAs in primary glioblastoma. Biochemical and Biophysical Research Communications 334 1351-1358. (doi:10.1016/j.bbrc.2005. 07.030)

Coussens LM \& Werb Z 2002 Inflammation and cancer. Nature 420 860-867. (doi:10.1038/nature01322)

Direkze NC, Hodivala-Dilke K, Jeffery R, Hunt T, Poulsom R, Oukrif D, Alison MR \& Wright NA 2004 Bone marrow contribution to tumorassociated myofibroblasts and fibroblasts. Cancer Research 64 8492-8495. (doi:10.1158/0008-5472.CAN-04-1708)

Du T \& Zamore PD 2005 microPrimer: the biogenesis and function of microRNA. Development 132 4645-4652. (doi:10.1242/dev.02070)

Dvorak HF 1986 Tumors: wounds that do not heal. Similarities between tumor stroma generation and wound healing. New England Journal of Medicine 315 1650-1659. (doi:10.1056/NEJM198612253152606)

Erez N, Truitt M, Olson P \& Hanahan D 2010 Cancer-associated fibroblasts are activated in incipient neoplasia to orchestrate tumor-promoting inflammation in an NF-кB-dependent manner. Cancer Cell 17 135-147. (doi:10.1016/j.ccr.2009.12.041)

Esquela-Kerscher A \& Slack FJ 2006 Oncomirs - microRNAs with a role in cancer. Nature Reviews. Cancer 6 259-269. (doi:10.1038/nrc1840)

Fang JH, Zhou HC, Zeng C, Yang J, Liu Y, Huang X, Zhang JP, Guan XY \& Zhuang SM 2011 MicroRNA-29b suppresses tumor angiogenesis, invasion, and metastasis by regulating matrix metalloproteinase 2 expression. Hepatology 54 1729-1740. (doi:10.1002/hep.24577)

Farmaki E, Chatzistamou I, Bourlis P, Santoukou E, Trimis G, Papavassiliou AG \& Kiaris H 2012 Selection of p53-deficient stromal cells in the tumor microenvironment. Genes \& Cancer 3 592-598. (doi:10.1177/1947601912474002)

Farmer P, Bonnefoi H, Anderle P, Cameron D, Wirapati P, Becette V, Andre S, Piccart M, Campone M, Brain E et al. 2009 A stroma-related gene signature predicts resistance to neoadjuvant chemotherapy in breast cancer. Nature Medicine 15 68-74. (doi:10.1038/nm.1908)

Fasanaro P, D'Alessandra Y, Di Stefano V, Melchionna R, Romani S, Pompilio G, Capogrossi MC \& Martelli F 2008 MicroRNA-210 modulates endothelial cell response to hypoxia and inhibits the receptor tyrosine kinase ligand Ephrin-A3. Journal of Biological Chemistry 283 15878-15883. (doi:10.1074/jbc.M800731200)

Feng R, Chen X, Yu Y, Su L, Yu B, Li J, Cai Q, Yan M, Liu B \& Zhu Z 2010 miR-126 functions as a tumour suppressor in human gastric cancer. Cancer Letters 298 50-63. (doi:10.1016/j.canlet.2010.06.004)

Finak G, Bertos N, Pepin F, Sadekova S, Souleimanova M, Zhao H, Chen H, Omeroglu G, Meterissian S, Omeroglu A et al. 2008 Stromal gene expression predicts clinical outcome in breast cancer. Nature Medicine 14 518-527. (doi:10.1038/nm1764)

Folkman J 1971 Tumor angiogenesis: therapeutic implications. New England Journal of Medicine 285 1182-1186. (doi:10.1056/ NEJM197108122850711)

Friedman RC, Farh KK, Burge CB \& Bartel DP 2009 Most mammalian mRNAs are conserved targets of microRNAs. Genome Research 19 92-105. (doi:10.1101/gr.082701.108)

Garzon R, Marcucci G \& Croce CM 2010 Targeting microRNAs in cancer: rationale, strategies and challenges. Nature Reviews. Drug Discovery 9 775-789. (doi:10.1038/nrd3179)

Guo C, Sah JF, Beard L, Willson JK, Markowitz SD \& Guda K 2008 The noncoding RNA, miR-126, suppresses the growth of neoplastic cells by targeting phosphatidylinositol 3-kinase signaling and is frequently 
lost in colon cancers. Genes, Chromosomes \& Cancer 47 939-946. (doi:10.1002/gcc.20596)

Guo G, Marrero L, Rodriguez P, Del Valle L, Ochoa A \& Cui Y 2013 Trp53 inactivation in the tumor microenvironment promotes tumor progression by expanding the immunosuppressive lymphoid-like stromal network. Cancer Research 73 1668-1675. (doi:10.1158/00085472.CAN-12-3810)

Haddow A 1972 Molecular repair, wound healing, and carcinogenesis: tumor production a possible overhealing? Advances in Cancer Research 16 181-234.

Harris AL 2002 Hypoxia - a key regulatory factor in tumour growth. Nature Reviews. Cancer 2 38-47. (doi:10.1038/nrc704)

Hayward SW, Wang Y, Cao M, Hom YK, Zhang B, Grossfeld GD, Sudilovsky D \& Cunha GR 2001 Malignant transformation in a nontumorigenic human prostatic epithelial cell line. Cancer Research 61 8135-8142.

He L, Thomson JM, Hemann MT, Hernando-Monge E, Mu D, Goodson S, Powers S, Cordon-Cardo C, Lowe SW, Hannon GJ et al. 2005 A microRNA polycistron as a potential human oncogene. Nature 435 828-833. (doi:10.1038/nature03552)

Hembruff SL, Jokar I, Yang L \& Cheng N 2010 Loss of transforming growth factor- $\beta$ signaling in mammary fibroblasts enhances CCL2 secretion to promote mammary tumor progression through macrophagedependent and -independent mechanisms. Neoplasia 12 425-433.

Hockel M, Schlenger K, Aral B, Mitze M, Schaffer U \& Vaupel P 1996 Association between tumor hypoxia and malignant progression in advanced cancer of the uterine cervix. Cancer Research 56 4509-4515.

Iorio MV, Ferracin M, Liu CG, Veronese A, Spizzo R, Sabbioni S, Magri E, Pedriali M, Fabbri M, Campiglio M et al. 2005 MicroRNA gene expression deregulation in human breast cancer. Cancer Research 65 7065-7070. (doi:10.1158/0008-5472.CAN-05-1783)

Ishii G, Sangai T, Oda T, Aoyagi Y, Hasebe T, Kanomata N, Endoh Y, Okumura C, Okuhara Y, Magae J et al. 2003 Bone-marrow-derived myofibroblasts contribute to the cancer-induced stromal reaction. Biochemical and Biophysical Research Communications 309 232-240. (doi:10.1016/S0006-291X(03)01544-4)

Kiaris H, Chatzistamou I, Trimis G, Frangou-Plemmenou M, Pafiti-Kondi A \& Kalofoutis A 2005 Evidence for nonautonomous effect of p53 tumor suppressor in carcinogenesis. Cancer Research 65 1627-1630. (doi:10.1158/0008-5472.CAN-04-3791)

Kiaris H, Trimis G \& Papavassiliou AG 2008 Regulation of tumor-stromal fibroblast interactions: implications in anticancer therapy. Current Medicinal Chemistry 15 3062-3067. (doi:10.2174/ 092986708786848596)

Kim JH, Oh S-H, Kim E-J, Park SJ, Hong SP, Cheon JH, Kim TI \& Kim WH 2012 The role of myofibroblasts in upregulation of S100A8 and S100A9 and the differentiation of myeloid cells in the colorectal cancer microenvironment. Biochemical and Biophysical Research Communications 423 60-66. (doi:10.1016/j.bbrc.2012.05.081)

Kozomara A \& Griffiths-Jones S 2011 miRBase: integrating microRNA annotation and deep-sequencing data. Nucleic Acids Research 39 D152-D157. (doi:10.1093/nar/gkq1027)

Kulshreshtha R, Ferracin M, Negrini M, Calin GA, Davuluri RV \& Ivan M $2007 a$ Regulation of microRNA expression: the hypoxic component. Cell Cycle 6 1426-1431. (doi:10.4161/cc.6.12.4410)

Kulshreshtha R, Ferracin M, Wojcik SE, Garzon R, Alder H, Agosto-Perez FJ, Davuluri R, Liu CG, Croce CM, Negrini M et al. 2007b A microRNA signature of hypoxia. Molecular and Cellular Biology 27 1859-1867. (doi:10.1128/MCB.01395-06)

Kurose K, Gilley K, Matsumoto S, Watson PH, Zhou XP \& Eng C 2002 Frequent somatic mutations in PTEN and TP53 are mutually exclusive in the stroma of breast carcinomas. Nature Genetics 32 355-357. (doi:10.1038/ng1013)

Lafkas D, Trimis G, Papavassiliou AG \& Kiaris H 2008 P53 mutations in stromal fibroblasts sensitize tumors against chemotherapy. International Journal of Cancer 123 967-971. (doi:10.1002/ijc.23546) http://erc.endocrinology-journals.org DOI: 10.1530/ERC-13-0119 Printed in Great Britain
(C) 2013 Society for Endocrinology
Lau NC, Lim LP, Weinstein EG \& Bartel DP 2001 An abundant class of tiny RNAs with probable regulatory roles in Caenorhabditis elegans. Science 294 858-862. (doi:10.1126/science.1065062)

Lee RC \& Ambros V 2001 An extensive class of small RNAs in Caenorhabditis elegans. Science 294 862-864. (doi:10.1126/science.1065329)

Lee RC, Feinbaum RL \& Ambros V 1993 The C. elegans heterochronic gene lin-4 encodes small RNAs with antisense complementarity to lin-14. Cell 75 843-854. (doi:10.1016/0092-8674(93)90529-Y)

Liao D, Luo Y, Markowitz D, Xiang R \& Reisfeld RA 2009 Cancer associated fibroblasts promote tumor growth and metastasis by modulating the tumor immune microenvironment in a $4 \mathrm{~T} 1$ murine breast cancer model. PLoS ONE 4 e7965. (doi:10.1371/journal.pone.0007965)

Liu CG, Calin GA, Meloon B, Gamliel N, Sevignani C, Ferracin M, Dumitru CD, Shimizu M, Zupo S, Dono M et al. 2004 An oligonucleotide microchip for genome-wide microRNA profiling in human and mouse tissues. PNAS 101 9740-9744. (doi:10.1073/pnas.0403293101)

Liu JL, Jiang L, Lin QX, Deng CY, Mai LP, Zhu JN, Li XH, Yu XY, Lin SG \& Shan ZX 2012 MicroRNA 16 enhances differentiation of human bone marrow mesenchymal stem cells in a cardiac niche toward myogenic phenotypes in vitro. Life Sciences 90 1020-1026. (doi:10.1016/j.lfs.2012. 05.011)

Lu J, Getz G, Miska EA, Alvarez-Saavedra E, Lamb J, Peck D, Sweet-Cordero A, Ebert BL, Mak RH, Ferrando AA et al. 2005 MicroRNA expression profiles classify human cancers. Nature 435 834-838. (doi:10.1038/nature03702)

Lu P, Weaver VM \& Werb Z 2012 The extracellular matrix: a dynamic niche in cancer progression. Journal of Cell Biology 196 395-406. (doi:10.1083/ jcb.201102147)

Michael MZ, O' Connor SM, van Holst Pellekaan NG, Young GP \& James RJ 2003 Reduced accumulation of specific microRNAs in colorectal neoplasia. Molecular Cancer Research 1 882-891.

Micke P \& Ostman A 2005 Exploring the tumour environment: cancerassociated fibroblasts as targets in cancer therapy. Expert Opinion on Therapeutic Targets 9 1217-1233. (doi:10.1517/14728222.9.6.1217)

Mitra AK, Zillhardt M, Hua Y, Tiwari P, Murmann AE, Peter ME \& Lengyel E 2012 MicroRNAs reprogram normal fibroblasts into cancer-associated fibroblasts in ovarian cancer. Cancer Discovery 2 1100-1108. (doi:10.1158/2159-8290.CD-12-0206)

Musumeci M, Coppola V, Addario A, Patrizii M, Maugeri-Sacca M, Memeo L, Colarossi C, Francescangeli F, Biffoni M, Collura D et al. 2011 Control of tumor and microenvironment cross-talk by miR-15a and miR-16 in prostate cancer. Oncogene 30 4231-4242. (doi:10.1038/onc.2011.140)

Nelson KM \& Weiss GJ 2008 MicroRNAs and cancer: past, present, and potential future. Molecular Cancer Therapeutics 7 3655-3660. (doi:10.1158/1535-7163.MCT-08-0586)

O'Donnell KA, Wentzel EA, Zeller KI, Dang CV \& Mendell JT 2005 c-Myc-regulated microRNAs modulate E2F1 expression. Nature $\mathbf{4 3 5}$ 839-843. (doi:10.1038/nature03677)

Olumi AF, Grossfeld GD, Hayward SW, Carroll PR, Tlsty TD \& Cunha GR 1999 Carcinoma-associated fibroblasts direct tumor progression of initiated human prostatic epithelium. Cancer Research 59 5002-5011.

Orimo A, Gupta PB, Sgroi DC, Arenzana-Seisdedos F, Delaunay T, Naeem R, Carey VJ, Richardson AL \& Weinberg RA 2005 Stromal fibroblasts present in invasive human breast carcinomas promote tumor growth and angiogenesis through elevated SDF-1/CXCL12 secretion. Cell 121 335-348. (doi:10.1016/j.cell.2005.02.034)

Paland N, Kamer I, Kogan-Sakin I, Madar S, Goldfinger N \& Rotter V 2009 Differential influence of normal and cancer-associated fibroblasts on the growth of human epithelial cells in an in vitro cocultivation model of prostate cancer. Molecular Cancer Research 7 1212-1223. (doi:10.1158/1541-7786.MCR-09-0073)

Pasquinelli AE, Reinhart BJ, Slack F, Martindale MQ, Kuroda MI, Maller B, Hayward DC, Ball EE, Degnan B, Muller P et al. 2000 Conservation of the sequence and temporal expression of let-7 heterochronic regulatory RNA. Nature 408 86-89. (doi:10.1038/35040556) 
Patocs A, Zhang L, Xu Y, Weber F, Caldes T, Mutter GL, Platzer P \& Eng C 2007 Breast-cancer stromal cells with TP53 mutations and nodal metastases. New England Journal of Medicine 357 2543-2551. (doi:10.1056/NEJMoa071825)

Petersen OW, Nielsen HL, Gudjonsson T, Villadsen R, Rank F, Niebuhr E, Bissell MJ \& Ronnov-Jessen L 2003 Epithelial to mesenchymal transition in human breast cancer can provide a nonmalignant stroma. American Journal of Pathology 162 391-402. (doi:10.1016/S00029440(10)63834-5)

Png KJ, Halberg N, Yoshida M \& Tavazoie SF 2012 A microRNA regulon that mediates endothelial recruitment and metastasis by cancer cells. Nature 481 190-194. (doi:10.1038/nature10661)

Porter DC, Farmaki E, Altilia S, Schools GP, West DK, Chen M, Chang BD, Puzyrev AT, Lim CU, Rokow-Kittell R et al. 2012 Cyclin-dependent kinase 8 mediates chemotherapy-induced tumor-promoting paracrine activities. PNAS 109 13799-13804. (doi:10.1073/pnas.1206906109)

Qin L, Chen Y, Niu Y, Chen W, Wang Q, Xiao S, Li A, Xie Y, Li J, Zhao X et al. 2010 A deep investigation into the adipogenesis mechanism: profile of microRNAs regulating adipogenesis by modulating the canonical Wnt/ $\beta$-catenin signaling pathway. BMC Genomics 11320. (doi:10.1186/1471-2164-11-320)

Raz Y \& Erez N 2013 An inflammatory vicious cycle: Fibroblasts and immune cell recruitment in cancer. Experimental Cell Research [in press]. (doi:10.1016/j.yexcr.2013.03.022)

Reinhart BJ, Slack FJ, Basson M, Pasquinelli AE, Bettinger JC, Rougvie AE, Horvitz HR \& Ruvkun G 2000 The 21-nucleotide let-7 RNA regulates developmental timing in Caenorhabditis elegans. Nature 403 901-906. (doi:10.1038/35002607)

Ronnov-Jessen L \& Petersen OW 1993 Induction of $\alpha$-smooth muscle actin by transforming growth factor- $\beta 1$ in quiescent human breast gland fibroblasts. Implications for myofibroblast generation in breast neoplasia. Laboratory Investigation 68 696-707.

Ruvkun G 2001 Molecular biology. Glimpses of a tiny RNA world. Science 294 797-799. (doi:10.1126/science.1066315)
Sachdeva M, Zhu S, Wu F, Wu H, Walia V, Kumar S, Elble R, Watabe K \& Mo YY 2009 p53 represses c-Myc through induction of the tumor suppressor miR-145. PNAS 106 3207-3212. (doi:10.1073/pnas.0808042106)

Soon PS, Kim E, Pon CK, Gill AJ, Moore K, Spillane AJ, Benn DE \& Baxter RC 2013 Breast cancer-associated fibroblasts induce epithelialto-mesenchymal transition in breast cancer cells. Endocrine-Related Cancer 20 1-12. (doi:10.1530/ERC-12-0227)

Trimboli AJ, Cantemir-Stone CZ, Li F, Wallace JA, Merchant A, Creasap N, Thompson JC, Caserta E, Wang H, Chong JL et al. 2009 Pten in stromal fibroblasts suppresses mammary epithelial tumours. Nature 461 1084-1091. (doi:10.1038/nature08486)

Ucar A, Vafaizadeh V, Jarry H, Fiedler J, Klemmt PA, Thum T, Groner B \& Chowdhury K 2010 miR-212 and miR-132 are required for epithelial stromal interactions necessary for mouse mammary gland development. Nature Genetics 42 1101-1108. (doi:10.1038/ng.709)

Wallace JA, Li F, Leone G \& Ostrowski MC 2011 Pten in the breast tumor microenvironment: modeling tumor-stroma coevolution. Cancer Research 71 1203-1207. (doi:10.1158/0008-5472.CAN-10-3263)

Xiong Y, Fang JH, Yun JP, Yang J, Zhang Y, Jia WH \& Zhuang SM 2010 Effects of microRNA-29 on apoptosis, tumorigenicity, and prognosis of hepatocellular carcinoma. Hepatology 51 836-845.

Yao Q, Cao S, Li C, Mengesha A, Kong B \& Wei M 2011 Micro-RNA-21 regulates TGF- $\beta$-induced myofibroblast differentiation by targeting PDCD4 in tumor-stroma interaction. International Journal of Cancer 128 1783-1792. (doi:10.1002/ijc.25506)

Zhang Y, Yang P, Sun T, Li D, Xu X, Rui Y, Li C, Chong M, Ibrahim T, Mercatali L et al. 2013 miR-126 and miR-126(*) repress recruitment of mesenchymal stem cells and inflammatory monocytes to inhibit breast cancer metastasis. Nature Cell Biology 15 284-294. (doi:10.1038/ ncb2690)

Zhao L, Sun Y, Hou Y, Peng Q, Wang L, Luo H, Tang X, Zeng Z \& Liu M 2012 MiRNA expression analysis of cancer-associated fibroblasts and normal fibroblasts in breast cancer. International Journal of Biochemistry \& Cell Biology 44 2051-2059. (doi:10.1016/j.biocel.2012.08.005)

Received in final form 10 July 2013

Accepted 21 July 2013

Made available online as an Accepted Preprint

22 July 2013
(C) 2013 Society for Endocrinology Printed in Great Britain 